\title{
"É Sempre Bom Ter o Nosso Dinheirinho": sobre a autonomia da mulher no extrativismo da mangaba no Pará
}

\author{
Thiara Fernandes ${ }^{1}$ e Dalva Maria Mota $^{2}$
}

\begin{abstract}
Resumo: $\mathrm{O}$ artigo tem por objetivo analisar o trabalho da mulher no extrativismo da mangaba sob o foco da autonomia. Um estudo de caso foi realizado na localidade de Espírito Santo, município de Maracanã, estado do Pará. Os principais procedimentos metodológicos foram a observação e a realização de entrevistas abertas e semiestruturadas. Três aspectos centrais são analisados: a organização do trabalho da mulher (na casa e no campo), os arranjos para beneficiamento e venda e o usufruto da renda gerada pelo trabalho no extrativismo. Os resultados demonstram que a maioria das mulheres $(66 \%)$ considera que tem autonomia na organização do trabalho e no uso da renda da venda dos frutos, o que contraria as pesquisas acadêmicas sobre a agricultura familiar em que o trabalho da mulher é, geralmente, subordinado ao do homem.
\end{abstract}

Palavras-chaves: Extrativismo, mangaba, trabalho de mulher, autonomia.

\begin{abstract}
The article is about the women's work in the extractivism of mangaba from the autonomy point of view. A case study was conducted in the Espirito Santo community in the county of Maracanã, in Pará State. Main methodological procedures were observation and open and semi-structured interviews. Three key aspects are analyzed: the organization of women's work (at home and in the field), the arrangements for processing and sale, and the benefits of the income generated by extractivism. The results show that most women $(66 \%)$ believe that they have autonomy in the way they organize their work and the use of income from the sale of fruits, which contradicts academic research on family farm in which women's work is generally subordinate to men.
\end{abstract}

Key-words: Extractivism, mangaba, women's work, autonomy.

Classificação JEL: Z13.

1. Mestre em Agriculturas Amazônicas e Desenvolvimento Sustentável. Coordenadora do Projeto de Desenvolvimento no Instituto Peabiru. E-mail: thiara@peabiru.org.br

2. Pós-doutora em Antropologia, pesquisadora da Embrapa Amazônia Oriental, bolsista de produtividade do CNPq. E-mail: dalva@cepatu.embrapa.br 


\section{Introdução}

Os estudos sobre o papel das mulheres na agricultura familiar geralmente analisam o trabalho realizado entre a casa e a roça (CORDEIRO, 2006; MELO, 2003; SILVA e PORTELLA, 2006) e identificam a desvalorização da força de trabalho das mulheres, habitualmente tratada como "ajuda" ao homem, mesmo quando elas trabalham mais ou tanto quanto eles ou executam as mesmas atividades (BRUMER, 2004).

Após estudar uma localidade rural do estado do Pará, Motta-Maués (1993) concluiu que não é a natureza do trabalho que o torna produtivo ou doméstico, é antes o sexo do indivíduo que o desenvolve. Nessa mesma perspectiva, D'Incao e Cotta Júnior (2001) constataram que a divisão sexual do trabalho situa-se mais no plano cultural das mentalidades do que no plano da força físico-biológica.

Diferente do que ocorre na agricultura, a literatura mostra que, em algumas atividades extrativistas, o trabalho da mulher destaca-se, proporcionando-lhe maior autonomia no acesso a espaços públicos e a recursos financeiros próprios. Permite, assim, que a mulher ultrapasse os espaços da casa e do campo, como analisam Simonian (1995), Araújo e Araújo (apud SIMONIAN, 2001) e Santos (2007). Apesar disso, nos dois casos acima as mulheres não têm o mesmo acesso que os homens à terra, aos finan- ciamentos, insumos, serviços públicos e instâncias decisórias, e essa realidade acaba por ser mais limitante à mulher nas atividades produtivas relacionadas à agricultura.

Não obstante essa constatação, existem poucas análises sobre o trabalho e a autonomia da mulher nas atividades extrativistas, o que nos instigou a escrever este artigo, cujo objetivo é analisar o trabalho da mulher no extrativismo da mangaba sob o foco da autonomia.

Por autonomia, compreende-se a possibilidade de autodeterminação do indivíduo para organizar e desenvolver seu trabalho, definindo os propósitos e agindo em consequência deles, assim como a capacidade de gerar renda e de decidir a forma como ela será utilizada, para gastos próprios ou não.

Entende-se que um dos aspectos críticos nas análises sobre o trabalho e a autonomia da mulher no espaço rural ou urbano está relacionado ao trabalho não remunerado que ocorre, principalmente, na esfera doméstica ${ }^{3}$. Apesar de

3. Como analisa Faria (2009), a economia clássica, que tem como momento fundador a publicação do livro de Adam Smith, A riqueza das nações (1776), tinha uma perspectiva histórica, preocupava-se com o trabalho que era visto como fonte do valor das mercadorias. A partir de 1870, perdeu sua força e foi substituído por duas outras correntes: de um lado, o neoclássico e, de outro, a abordagem marxista. Em todas essas correntes a perspectiva feminista e, em especial, a análise do trabalho doméstico teve pouca atenção. A única exceção foi a do economista clássico John Stuart Mill que, a partir da colaboração de Harriet Taylor, reconheceu 
a importância do tema ser compreendida e da constatação do desdobramento das mulheres para manter todos os membros da casa em situações de conforto paralelo ao seu trabalho no campo, este tema será mais aprofundado em próximos estudos.

A pesquisa foi realizada na localidade de Espírito Santo, situada em uma área denominada Campo da Mangaba ${ }^{4}$, local de grande incidência de mangabeiras e área de amortecimento da Reserva Extrativista Marinha Maracanã (Resex Maracanã) desde $2002^{5}$ a partir da institucionalização desse território. Predomina nessa área o acesso comum aos recursos naturais, com importante participação das mulheres nas atividades de coleta (SCHMITZ, MOTA e SILVA JÚNIOR, 2011).

Na realização deste estudo, duas grandes fases entrelaçadas ocorreram: revisão bibliográfica e de dados secundários e levantamento de dados primários. A pesquisa foi realizada por meio de um estudo de caso com as 15 famílias residentes na localidade ${ }^{6}$ de Espírito Santo. Os

o trabalho doméstico, mas não chegou a integrá-lo no conjunto da análise econômica. Outra incorporação que deve ser feita é a esfera da reprodução. As crianças que nascem não são apenas garantia de sustento para seus pais, mas para a sociedade como um todo (FOLBRE, 2001 apud PAULILO, 2004). Quando adultas, são elas que vão produzir, pagar impostos, gerar filhos e produzir o excedente para sustentar as novas crianças e os idosos. Por ter que arcar com maior parte do ônus da reprodução, as mulheres têm menores possibilidades de conseguir bons empregos. Não é difícil entender porque, entre os pobres do mundo, as mais pobres são as mulheres, de acordo com dados oficiais da conferência da ONU (1980) (PAULILO, 2004).

4. Área de $3.570,78$ hectares, encravada em um ecossistema antrópico de vegetação secundária. A cobertura vegetal é denominada "campos cerrados", cuja característica principal é a presença de espécies arbóreas baixas e tortuosas. Nesse local, estão estabelecidas 15 comunidades rurais (OLIVEIRA, PEREIRA e PAES, 2007) no entorno da Reserva Extrativista Marinha Maracanã (REM Maracanã).

5. Unidade de conservação de uso sustentável, criada pelo Decreto n. 4.340, de 13 de dezembro de 2002. Área de $30.018,88$ hectares, localizada na região da costa-mar do estado do Pará, pertencendo à mesorregião do Nordeste paraense e à microrregião do Salgado.

6. Aqui compreendida como um conjunto de relações políticas em curso, uma densidade na qual os lugares são discursiva e imaginariamente materializados e ordenados por meio das práticas de pessoas e de economias políticas diferentemente orientadas (RAFFLES, 1999, p. 324). principais procedimentos foram observações e entrevistas: as primeiras, por meio da participação nas atividades realizadas pelas mulheres nos espaços domésticos, nos campos onde praticam o extrativismo e nos locais onde vendem os frutos; as segundas, com todas elas, e também com outros membros da família, a partir de roteiros semiestruturados e estruturados sobre a organização e a realização das atividades de coleta, beneficiamento e venda dos frutos. O debate teórico que sustenta as análises refere-se principalmente à divisão social do trabalho, à autonomia, ao extrativismo e ao trabalho da mulher no espaço rural.

Considerando-se este quadro, as seguintes questões orientam a reflexão neste artigo: Como tem sido realizado o trabalho das mulheres no extrativismo no que diz respeito à organização das atividades e à realização da coleta? Quais os arranjos instituídos no grupo doméstico para viabilizar a atividade? Como elas têm lidado com o dinheiro da venda dos frutos? À luz da definição aqui utilizada, como se evidencia a autonomia?

O artigo constitui-se de três partes, além desta introdução. Na primeira, trata-se do debate sobre o extrativismo e a autonomia da mulher, tendo como referência estudos realizados na perspectiva tanto do trabalho da mulher na agricultura quanto no extrativismo. Na segunda, descreve-se como se realiza o extrativismo da mangaba naquela localidade em associação com outras atividades, privilegiando o papel das mulheres. $\mathrm{Na}$ terceira, evidenciamos os arranjos ${ }^{7}$ instituídos na divisão do trabalho nos grupos domésticos, destacando o destino da renda obtida com a venda dos frutos. Por fim, a conclusão indica os principais traços do que é identificado como autonomia para aquele contexto.

7. Compreende-se arranjos na perspectiva adotada por Woortmann e Woortmann (2004, p. 29). Para os autores, "arranjo" diz respeito a situações conjunturais, enquanto "estrutura" refere-se a algo permanente (ou com relativa permanência). 


\section{O extrativismo e a autonomia da mulher}

Se nos estudos sobre as mulheres na agricultura autores verificam a invisibilidade do seu trabalho e sua pouca autonomia em relação à força de trabalho e aos recursos gerados, no extrativismo, o tema tem sido examinado em perspectivas diferenciadas: vai-se da invisibilidade de seu trabalho (no caso das seringueiras) à conquista do espaço público e midiático por conta de suas lutas (no caso das quebradeiras de coco-babaçu, das catadoras de mangaba, das licurizeiras, entre outras).

$\mathrm{Na}$ agricultura de caráter familiar, as análises mostram que o trabalho é desenvolvido tanto por homens quanto por mulheres. Em muitos casos, à mulher é atribuído o papel de "ajuda", mesmo quando ela trabalha mais ou tanto quanto o homem. Em geral, a renda da venda dos produtos é administrada por ele. Além disso, muito raramente, o planejamento da atividade no estabelecimento é compartilhado pelo casal, cabendo geralmente ao homem tal ação. Por fim, estudos demonstram que o extrativismo oferece à mulher mais condições para organizar e desenvolver a atividade a partir de sua força de trabalho, além do usufruto da renda gerada com a comercialização dos produtos.

Simonian (1995) descreve as atividades das mulheres nos seringais e castanhais da Amazônia brasileira, discutindo em seu trabalho a categoria "mulheres da floresta", que já havia sido cunhada por Murphy e Murphy (1974) em etnografia, sobre os índios mundurucus no Brasil nos anos 50 do século XX. Não obstante as diferenças entre os dois grupos, as análises dos autores permitem constatar que não somente essas mulheres situam-se em contextos de floresta, como também integram, produzem e recriam a cultura local, com dimensões sociais, ideológicas e simbólicas igualmente importantes.

Em se tratando das mulheres não indígenas estudadas por Simonian (1995), elas caracterizam-se por seu envolvimento com as atividades de extrativismo vegetal, de caça e pesca, volta- das para o aprovisionamento da família, e ainda mantêm uma relação mítico-espiritual com os ecossistemas florestais, ribeirinhos e lacustres onde vivem. Essas mulheres conhecem, utilizam e comercializam os recursos naturais no seu cotidiano, empenhando-se também em sua preservação. Não obstante, a produção acadêmica sobre o trabalho das mulheres nos seringais é escassa, conforme aponta a autora. Para ela, as poucas evidências focalizavam a crueldade com que as mulheres eram tratadas.

A ideia de que o trabalho é pesado e perigoso parece ter desempenhado um papel importante na persistência do silêncio sobre a existência de mulheres seringueiras (CABRAL apud SIMONIAN, 2001). O imaginário que concebe a atividade seringueira como masculina parece ter sido internalizado. Assim sendo, a mulher extrativista naqueles espaços não desempenha o papel social determinado para ela e, portanto, sofre as medidas repressivas da sociedade. Seu não reconhecimento como trabalhadora extrativista é uma delas, conforme sugere Simonian (2001) em sua análise.

Sobre o trabalho da mulher no extrativismo da castanha-do-brasil, também são poucos os registros na literatura acadêmica. Simonian (2001) descreve a "cultura da castanha", relacionando a atividade extrativista com os modos de vida locais e os diversos usos e conhecimentos sobre a planta e sua transformação tanto para a culinária como para a medicina popular, afirmando que a mulher tem importância fundamental na manutenção dessa cultura.

Com base em um balanço do trabalho da autora, chegou-se à constatação de que existem diferenças significativas no papel da mulher nas atividades extrativistas da castanha e da seringueira no que se refere à autonomia. No primeiro caso, a atividade é desenvolvida em regime familiar, com a permanência de membros do grupo doméstico no castanhal durante toda a safra. Apesar de a mulher participar do trabalho de coleta, transporte e beneficiamento, é o homem, na maioria dos casos, o principal responsável pelo trabalho e pela comercialização. Por 
outro lado, no segundo caso, as mulheres, além de participarem de todo o processo produtivo, também atuam na comercialização da produção (SIMONIAN, 2001). Portanto, elas têm inserções diferenciadas e exercem maior autonomia apenas no caso em que têm possibilidade de planejar o trabalho e têm acesso e controle sobre os recursos financeiros gerados.

Não obstante essas diferentes características, no geral, a mulher, no extrativismo vegetal, sofre tentativas de silêncio e de negação, que são enfrentadas por alguns grupos, como é o caso das mulheres que trabalham na extração do coco-babaçu na Amazônia Oriental, as denominadas "quebradeiras de coco-babaçu". Seu trabalho é fundamental para a reprodução social dos seus grupos, principalmente com a intensificação da monetarização das relações no campo (SIMONIAN, 2001). Foi também a partir desse marco que os homens passaram a participar desse tipo de atividade, mas dificilmente eles são identificados como quebradores de coco, o que ratifica ser a quebra do coco-babaçu uma atividade concebida como tipicamente feminina, ou seja, decorrente de um processo de reconhecimento social.

Mesmo que a literatura mostre que a tecnificação dos processos e o aumento do valor dos produtos extrativistas nos mercados tendem a expulsar as mulheres da atividade, no extrativismo do coco-babaçu e também da mangaba, esse fato não tem sido confirmado. Em relação ao passado, os produtos têm hoje maior valor econômico e maior diversidade em se tratando da agregação de valor, mas seu extrativismo continua sendo uma atividade predominantemente feita pelas mulheres, quer seja por disposições culturais, quer pelo intuito de reforço do reconhecimento conquistado, quer seja ainda pela garantia de acesso a recursos (FIGUEIREDO, 2005; MOTA et al., 2008a; SANTOS, 2007).

No caso do extrativismo da mangaba, a análise desses aspectos tem sido intensificada na última década, particularmente quanto ao papel das mulheres no extrativismo, à divisão do trabalho, à mobilização política e à conquista de uma identidade (MOTA, SCHMITZ e FREITAS, 2007;
MOTA, SCHMITZ e SILVA JÚNIOR, 2007; MOTA et al., 2008a, 2008b, 2010, 2011a, 2011b; PEREIRA, 2008; SANTOS, 2007; SCHMITZ, MOTA e SILVA JÚNIOR, 2011). Apesar da riqueza das análises sobre o tema, nenhum dos autores mencionados tem tratado diretamente a questão da autonomia das mulheres. Entretanto, oferecem pistas para a discussão do tema ao destacarem que o trabalho das mulheres no processo produtivo e na comercialização representa uma possibilidade de autonomia, mediante a perspectiva de organizar e gerenciar seu trabalho e o controle da renda derivada da venda dos frutos, fundamental para o sustento das famílias. O aporte de recursos por elas realizado influi, inclusive, na transformação de valores culturais relacionados à atividade e a quem a exerce (SANTOS, 2007).

Nesse debate, a autonomia é entendida como constituída por dois aspectos: i) a autodeterminação para organizar e desenvolver o trabalho, definindo os próprios objetivos e agindo em consequência deles; ii) a capacidade de gerar renda e de decidir a forma como essa renda será utilizada - para gastos próprios ou com a família.

Tendo como pressuposto que todas as atividades alusivas ao extrativismo da mangaba no Norte e no Nordeste do Brasil são predominantemente realizadas por mulheres, analisamos neste artigo um grupo de mulheres extrativistas no município de Maracanã, no Nordeste paraense. O foco da reflexão deste artigo é a autonomia no trabalho e no uso da renda gerada pela atividade.

\section{O extrativismo da mangaba na localidade de Espírito Santo}

A memória oral registra que as primeiras famílias residentes na localidade denominada de Espírito Santo se instalaram nos anos 40 do século XX. Ali, informadas pelas suas experiências anteriores, elas construíram regras de acesso aos recursos da natureza (terra, floresta e rios), assumindo, com os moradores das localidades vizinhas, o controle de extensões mais inclusivas 
- os territórios ${ }^{8}$, dentro dos quais se situam tanto áreas de uso e domínio particular quanto áreas de uso e domínio comuns (ESTERCI, 2005).

Em 2009, 15 famílias compunham a localidade. Em nove delas, algum membro praticava o extrativismo da mangaba como parte do conjunto de atividades realizadas pelo grupo doméstico, num dado espaço, ao longo do tempo localmente demarcado pelos ciclos da natureza. Assim, tempos de extrativismo (animal e vegetal) somam-se a tempos de plantio, de colheita e de fabricação de farinha.

Na localidade de Espírito Santo, as mulheres extrativistas usam a expressão apanhadoras de mangaba para se autodesignarem, diferente de um grupo de mulheres no Nordeste do Brasil, que se autodesignam "catadoras de mangaba" (MOTA et al., 2011a), tendo, inclusive, assumido a identidade política de "catadoras de mangaba" e constituído um movimento no espaço público para fins de interlocução com o Estado e a sociedade civil. É importante destacar que nem todos os grupos que praticam o extrativismo da mangaba no Brasil organizam-se como tal, nem se aglutinam em torno do Movimento das Catadoras de Mangaba, que hoje atua no Sergipe.

Vistas com outro olhar, as diferentes classificações provavelmente estão também relacionadas às formas como as mulheres extrativistas coletam o fruto. No Nordeste brasileiro, as mulheres tanto catam do chão as mangabas, classificando esse fruto como mangaba de caída (MOTA et al., 2008b), como as coletam nas árvores, classificando o fruto como mangaba de vez. As apanhadoras de mangaba na localidade de Espírito Santo tiram o fruto da árvore. Diferentes compreensões coexistem quanto à qualidade dos frutos nas duas situações. No Nordeste, a mangaba de caída é a mais apreciada, considerada mais saborosa pelas extrativistas e pelos consumidores. No Norte, as

8. As terras conferidas a esses grupos são dadas efetivamente na perspectiva de um território cultural, em que se faça possível exatamente a existência desses grupos de acordo com os padrões culturais próprios de uma vida plasmada, gestada e definida pelos próprios grupos (ALMEIDA e PEREIRA, 2003, p. 247). apanhadoras de mangaba consideram que a mangaba do chão não é boa para o consumo, por já estar, acreditam, em processo de apodrecimento.

Das 15 famílias que compõem a localidade, nove desenvolvem o extrativismo da mangaba e consideram a atividade como muito importante para a composição da renda familiar. Os membros dessas famílias responsáveis por desenvolver a atividade em três casos são os casais; em outros três casos, são as mulheres e, em mais três casos, são homens. Embora homens e mulheres realizem a atividade, esta análise foi direcionada para a atividade da mulher nas diferentes situações observadas (como principal responsável, compartilhando a responsabilidade com o marido e sob a coordenação do marido).

\subsection{Entre campo e casa: "apanhar a mangaba"}

Durante a safra da mangaba, de setembro a fevereiro, nos dias em que as mulheres vão ao campo para apanhar o fruto, a dinâmica do trabalho na casa adapta-se ao trabalho extrativista. Segundo informam as entrevistadas, elas escolhem a comida cujo preparo é mais simples (enlatado, ovo etc.) para terem menos obrigações e ficarem livres dos afazeres da casa, dedicando-se ao trabalho de apanhar a mangaba. Em alguns casos, outras parentas mulheres ficam responsáveis pelo preparo do almoço. Além disso, algumas tarefas domésticas são delegadas às filhas, preferencialmente, e também aos filhos. Observa-se, nessas iniciativas, uma importante rede de solidariedade por meio da troca de serviços, comum nas economias de caráter familiar. Como observou Sabourin (2001, p. 41) em comunidades rurais do sertão nordestino, também na localidade de Espírito Santo "paralelamente às relações de câmbio mercantil, encontram-se prestações econômicas não mercantis que correspondem à permanência de práticas de reciprocidade camponesa, ancestrais ou readaptadas num contexto novo".

Algumas apanhadoras de mangaba desdobram-se para garantir tanto a atividade extrativista 
quanto os afazeres caseiros cotidianos, como podemos observar no depoimento a seguir:

Levanto as cinco, faço café e dou de comer às galinhas, lavo alguma louça e só encho água quando chego, faço tudo nas pressa, têm os meninos que vão pra escola, se eu não fizer, eles não fazem, vão de jejum pra aula. Saio às seis por causa de aproveitar o sol, às dez tô de volta em casa. De tarde minha filha lava a louça e enche água pra mim, uma hora já saio de novo e chego às quatro e meia da tarde (L. O. C., apanhadora de mangaba, 39 anos).

As idas ao campo sempre são feitas em duplas ou em grupos, e o que determina a escolha da companhia são os laços de parentesco, sendo muito corriqueiro ver sogra e nora indo juntas, bem como os casais, poucas vezes acompanhados pelos filhos. Outro fator que fortalece a escolha é a afinidade que facilita a fluidez das conversas, as trocas de informações e o relato de casos engraçados que tornam o trabalho mais agradável. Esses momentos revelam-se como espaços por excelência de sociabilidade naquele sentido apontado por Simmel (1983), nos quais o prazer da interação é o que importa. A sociabilidade tecida nos campos de coleta guarda semelhanças importantes com as análises de Mota et al. (2011b) sobre as catadoras de mangaba no Nordeste brasileiro, para as quais a satisfação da interação é uma forma de amenização da dureza do trabalho e de atualização dos vínculos afetivos e sociais.

Diferente das mulheres, os homens solteiros preferem ir sozinhos e os casados, em companhia de suas esposas, na maioria das vezes. Não foram observados grupos de homens na atividade, que parece ser estruturada, nas mentalidades e na prática, como mais associada às mulheres. A diferença observada permite-nos pensar em sociabilidades específicas, no caso, uma sociabilidade feminina constituída pelo agrupamento e pelo diálogo.

Para realizar a coleta, as apanhadoras de mangaba deslocam-se de 2 a $10 \mathrm{~km}$ dentro da área denominada Campo da Mangaba. Os homens percorrem maiores distâncias, geralmente com a utilização de bicicleta. As distâncias percorridas estão associadas à oferta do fruto de acordo com o período da safra. No início da safra, as mangabeiras mais próximas da localidade estão em franca produção; por isso, são as primeiras a serem visitadas para a coleta. Com a prática diária de extração, os frutos vão escasseando, o que obriga a apanhadora a procurar locais ainda não visitados.

Durante a caminhada, da localidade até a área, de preferência no Campo da Mangaba, as mulheres conversam sobre todo tipo de assunto, trocam conselhos e conhecimentos sobre o trabalho, além de assuntos pessoais. Elas também conversam sobre o que costumam chamar "os encantados". Elas explicam que existem pequenos seres encantados, que habitam o Campo da Mangaba, chamados "oiaras", que são como crianças e têm a pele negra. Segundo elas, muitas vezes as pequenas pegadas dos "oiaras" são identificadas no chão, e elas acreditam que são esses seres que fazem com que elas se percam umas das outras durante a atividade de coleta. Elas usam a expressão "ficar mundiado", para traduzir a falta de noção do local onde estão, um período de "cegueira". Segundo relatam, uma mulher pode estar apanhando mangaba em uma árvore e sua companheira, em outra árvore, ambas tão concentradas a ponto de passar de uma árvore para outra sem perceberem; quando atentam, estão muito longe do local em que imaginavam estar. Para elas, os "oiaras" são os responsáveis por sua desatenção: "Outro dia fiquei mundiada e fui parar perto do igapó, me perdi da velha Maria e voltei sozinha prá casa" (L. O., apanhadora de mangaba, 39 anos).

Mas outros sentidos também são atribuídos aos "oiaras", como a punição para os bêbados que por acaso se aventuram nas estradas do Campo da Mangaba, como expressa uma entrevistada: "Os oiaras gostam de bater nos bebum que andam pela estrada, vêm assim no finzinho da tarde, eles pegam e dão uma surra de cipó" (M. I., apanhadora de mangaba, 67 anos).

Durante a coleta, as mulheres comunicam-se por meio de gritos e assobios, quando percebem 
que estão distantes umas das outras, para evitar ficarem "mundiadas". Segundo as entrevistadas, "os encantados" vivem no subterrâneo da terra e saem nos horários de meio-dia e no final da tarde, não são em sua natureza maus ou bons, mas é necessário respeitá-los para não ser maltratado por eles. Para Ossami de Moura (2001), cada sociedade tem sua própria representação da natureza e essa representação está alicerçada principalmente na cultura.

Em se tratando da coleta propriamente dita, depois de caminhar para chegar ao local de preferência, cada mulher vai para uma planta, para não misturar os frutos de uma e de outra, como também foi observado em Sergipe por Mota et al. (2011b).

A apanhadora de mangaba usa as mãos para apanhar os frutos que estão nas plantas, mas ao seu alcance, colocando-os diretamente na cesta. Para apanhar os frutos que estão mais altos, elas utilizam o gancho até derrubá-los, então os pegam do chão e os colocam na cesta.

Os utensílios utilizados para a atividade resumem-se a uma cesta de tala de guarumã (Ischnosiphon arouma Koern), que é forrada com folhas, e a um gancho de arame preso a uma longa vara de madeira que as mulheres levam de suas casas para auxiliá-las na coleta dos frutos das árvores mais altas. O gancho constitui um elemento comum no extrativismo da mangaba em todas as regiões do Brasil, variando em formato, mas tendo sempre a mesma função, como atestaram Silva Júnior, Mota e Schmitz (2011) em suas expedições no Norte, Nordeste, Sudeste e Centro-Oeste.

Segundo as entrevistadas, existem muitas variedades de planta, uns frutos são mais avermelhados, outros, mais amarelados e alaranjados. Os frutos diferenciam-se não pelo tamanho ou pela cor, mas pelo estágio de amadurecimento, podendo ser brilhantes e viçosos quando maduros e opacos quando verdes.

À volta para casa é diferente da ida, principalmente pelas cestas cheias de mangaba, que são geralmente carregadas na cabeça, e pelo estado físico das mulheres, normalmente famintas e cansadas, segundo informam.
A maioria das extrativistas mantém esse ritmo 9 de trabalho de segunda a quarta-feira, durante toda a safra da mangaba, exceto as que têm filhos entre quatro e sete anos, que vão ao campo apenas no período da manhã, quando os filhos estão na escola. Em todos os casos, quinta e sexta-feira são os dias reservados para beneficiar o fruto, e aos sábados é feita a comercialização na feira da sede do município ou dos municípios vizinhos e em Belém, capital do Pará.

A apanhadora que pratica a atividade sozinha organiza e conduz o trabalho de coleta (quantidade de frutos, horas trabalhadas, locais visitados, frequência de visitas etc.) sem a interferência de terceiros. Em um dos casos em que a apanhadora desenvolve a atividade com o marido, é ele quem administra o seu trabalho; nos outros dois casos, o casal divide as tarefas.

\subsection{As atividades de beneficiamento da fruta: a arte de "empalhar"}

As apanhadoras de mangaba da localidade de Espírito Santo usam o termo empalhar para indicar o beneficiamento do fruto, realizado por meio da limpeza e do acondicionamento das mangabas em pequenos paneiros ${ }^{10}$ forrados com folhas para a comercialização.

$\mathrm{O}$ ato de empalhar tem duas funções, além da limpeza e da seleção dos frutos: i) abafar o fruto durante dois dias, aproximadamente, para finalizar o amadurecimento; ii) facilitar o seu transporte para os locais de venda. Para empalhar, os moradores locais usam folhas e talas da palmeira guarumã. As talas da haste caulinar da planta são usadas para a confecção dos paneiros e as folhas, para revesti-los, tornando-se, assim, a embalagem dos frutos.

A coleta da planta do guarumã é feita nas áreas de manguezal por homens, mulheres, jovens e crianças e não é considerada uma atividade pesada pela população local. Na maioria das

\footnotetext{
9. Com idas a campo nos dois períodos do dia, de manhã e à tarde.

10. Cestas artesanais feitas com tala de guarumã.
} 
vezes, no entanto, a apanhadora negocia com um dos filhos ou com o marido para que eles façam a extração e ela possa ocupar-se exclusivamente da coleta da mangaba. Também foi constatado que outras mulheres apanham mangaba durante todo o dia e retornam do campo algumas horas mais cedo, para aproveitar a luz do sol e extrair o guarumã que será por elas mesmas utilizado na confecção dos paneiros. O manguezal fica perto da localidade, o que facilita o trabalho. As mulheres gastam, em média, de duas a três horas por semana na extração do guarumã. Nessa prática, é observada uma complementaridade entre os recursos de diferentes ecossistemas (mangue, campos cerrados) e as práticas tradicionais, que não dependem de insumos externos para amadurecer e embalar os frutos.

Outros arranjos familiares são desenvolvidos na atividade de empalhar. Um casal coleta as frutas separadamente durante a semana, mas, para empalhar, o homem fica responsável por extrair o guarumã e confeccionar os paneirinhos para os dois e a mulher encarrega-se de limpar e embalar os frutos. No entanto, o marido não confecciona os paneirinhos sozinho, podendo contratar outro homem ou uma mulher para ajudá-lo. Nesse caso, segundo a mulher, a atividade de produção do paneirinho ocupa muito tempo e, por isso, ela prefere delegar a função a seu marido. Nesse arranjo, além de a mulher planejar seu trabalho, ela tem autonomia no controle da sua produção, arrumando os paneirinhos com as mangabas separadamente. Ocorre, então, uma troca de trabalho entre o casal para que se efetue o empalhamento dos frutos.

Além da fabricação do paneirinho, o trabalho de beneficiamento, chamado localmente de "empalhar a mangaba", começa com a seleção e a lavagem dos frutos. Essa primeira etapa é feita pela mulher, com a ajuda dos filhos. Os frutos são selecionados um a um, os muito maduros são reservados para o consumo de casa e os apodrecidos são descartados. Nesse momento, a apanhadora destaca o pedúnculo do fruto, que libera o látex, para evitar o acúmulo de sujeira nos frutos. Um a um, os frutos selecionados são depositados em um recipiente com água para a lavagem. Em seguida, são retirados da água e colocados numa grande peneira forrada com folhas, e conservados à sombra para secar naturalmente. Depois de secos, os frutos são embalados nos paneirinhos forrados com folhas de guarumã; em seguida, as folhas são fechadas e amarradas com uma corda ou cipó. Os frutos ficam empalhados por aproximadamente dois dias antes da comercialização.

As atividades de beneficiamento são feitas dentro de casa (no quintal e na cozinha) ou nos arredores, segundo a preferência e a disponibilidade de espaço de cada grupo doméstico. O trabalho de empalhar, na maioria das vezes, combina-se com os afazeres da casa e os cuidados com os filhos assumidos pelas mulheres que vivenciam cotidianamente a chamada "conciliação".

\subsection{Comercialização da mangaba: "marretar"}

O termo marretar designa localmente a ida às feiras da sede dos municípios ou à capital do estado para comercializar os frutos. Para isso, a apanhadora arruma cuidadosamente os paneirinhos em uma grande caixa de papelão ou de isopor, ou mesmo em um grande paneiro, e transporta-os da localidade de Espírito Santo até as feiras em ônibus ou barco, dependendo do local escolhido para a venda. Ali, os frutos poderão ser todos vendidos a um feirante ou aos consumidores finais.

Em 2010, um paneirinho de mangaba vendido ao consumidor final custava entre $\mathrm{R} \$ 1,50$ e R\$2,00, com o feirante pagando de $R \$ 1,00$ a $\mathrm{R} \$ 1,50$. Cada paneirinho contém aproximadamente $1,5 \mathrm{~kg}$ de mangaba.

Observamos que, quando a mangaba é vendida ao consumidor final, é possível obter maior lucro; é necessário, porém, dedicar uma manhã inteira a essa tarefa e ainda correr o risco de não vender todos os paneirinhos. Logo, vender ao feirante é mais seguro, porque toda a produção é vendida de uma vez. Tanto homens como mulheres têm preferência pela venda direta ao feirante para evitar riscos e também se desocupar mais cedo e poder cuidar de outros afazeres. 
Além da venda da mangaba, as apanhadoras aproveitam a ida à cidade para, com o dinheiro obtido na venda da mangaba, comprar o que chamam "a despesa da casa" e outros produtos que não são vendidos na localidade, além de pagar as contas da família, como a prestação de algum eletrodoméstico, por exemplo.

\section{Arranjos instituídos na divisão do trabalho nos grupos domésticos}

Em relação aos arranjos familiares para desenvolver o trabalho do extrativismo da mangaba, quatro possibilidades foram identificadas (Tabela 1).

No tipo 1, o casal realiza as atividades de coleta separadamente e divide as tarefas ligadas ao beneficiamento, enquanto somente o homem pratica a comercialização. Apenas um grupo doméstico compõe esse primeiro arranjo, sendo constituído por pais com filhos crianças e adolescentes. No entanto, ainda que o homem comercialize toda a produção do casal, ele sempre entrega à esposa o valor em dinheiro obtido com a venda da parte dela da produção, e os dois usam o dinheiro de forma diferente. Ele compra alimentos, roupas e calçados para todos os membros; já a mulher, apesar de usar seu dinheiro geralmente com o mesmo fim, guarda uma parte para prevenir eventualidades no decorrer do ano, principalmente relacionadas à saúde da família. Esse dinheiro guardado também é usado em alguma viagem que ela faça às localidades vizinhas ou a outros municípios para visitar parentes. Além disso, ela também compra roupas, para ela, calçados, eletrodomésticos e ração, para alimentar os pequenos animais criados no quintal, cuja venda ou cujo consumo são por ela administrados.

Na localidade de Espírito Santo, a criação de galinha caipira é uma atividade prioritariamente de mulheres. A safra da mangaba também coincide com um período em que o milho já foi colhido nas roças, e as reservas que foram guardadas já estão esgotadas. Uma dessas mulheres dá seu depoimento sobre o uso dos recursos financeiros:

a despesa [da casa] é do marido, ele compra roupa e calçado pra mim e pros filho. Quando tem mais, pode até tirar alguma coisa na loja, vamos apanhar mangaba pra comprar um colchão pra cama esse ano. [...] ele vai vender a dele e leva a minha, quanto ele faz na minha, ele me dá, ele me dá todo o dinheiro das minhas, e das dele, ele compra coisa pra casa. Eu gosto sempre de guardar um pouquinho porque quando a gente adoece, aqui é interior! [...] sempre quem vai com os filho [para a sede do município ou a capital do estado em caso de doença] sou eu, ele me dá, mas eu gosto de ter também, é bom ter o nosso dinheirinho! Ele nem sabe que eu tenho. Esse ano nós vamos plantar mandioca e milho, a roça é só pra gente comer. [...] É mais no tempo da mangaba que a gente vai tirando nosso paneirinho e a gente defende, no tempo da mangaba a gente ajuda em casa, porque se quer alguma coisa, compra, se não fosse frete e passagem era melhor. Do ano passado [2009] até julho [de 2010] eu ainda tinha [dinheiro da venda da mangaba], em julho eu gastei, fui no Bom Jardim [localidade vizinha, onde mora sua família, pai, mãe e irmãos] (L. O. C., apanhadora de mangaba, 39 anos).

Foi constatado que, nesse arranjo, a mulher tem autonomia tanto no uso de sua força de tra-

Tabela 1. Tipologia da divisão de trabalho no extrativismo da mangaba na localidade de Espírito Santo, Maracanã, PA

\begin{tabular}{ccccc}
\hline Tipos & № de grupos domésticos & Apanhar & Empalhar & Marretar \\
\hline 1 & 1 & Separados & Juntos & Homem \\
2 & 3 & Juntos & Juntos & Alternam \\
3 & 2 & Mulher & Mulher & Mulher \\
4 & 3 & Homem & Homem & Homem \\
\hline
\end{tabular}

Fonte: Fernandes (2010). Sistematização de pesquisa de campo. 
balho quanto no uso da renda, apesar de não ser ela quem vende o produto. Ela tem direito e domínio sobre os recursos gerados com sua força de trabalho.

No tipo 2, os três casais desenvolvem juntos as atividades de extrativismo e beneficiamento. A comercialização pode ser feita pelo casal juntos ou separadamente. Os grupos domésticos que compõem esse arranjo são constituídos pelos pais com filhos em todas as idades, e cada casal tem de três a cinco filhos.

Quando apenas um vai à feira marretar, tanto o homem quanto a mulher vende toda a produção do casal. Quando juntos, eles dividem o trabalho, que consiste principalmente em carregar e transportar os cestos e oferecer os frutos.

Esses casais marretam a mangaba nas feiras da região metropolitana de Belém, na feira de Marituba e na sede do município de Maracanã.

Das apanhadoras desse arranjo, apenas uma se desloca até a capital, sozinha ou na companhia do marido, para vender o fruto. Essa mulher é ex-moradora de Marituba, tendo contato com os feirantes; além disso, parte de sua família continua morando na região, o que facilita sua estadia no local.

Nos outros casos, são os homens que fazem a viagem e a venda na capital enquanto as mulheres vão apenas até a sede do município. Nesse caso, o dinheiro provindo da comercialização é usado para a despesa da casa e o excedente, para a compra de roupas e calçados. Quem se desloca até a feira para vender a mangaba também é responsável pelas compras da despesa da casa, usando o dinheiro obtido com a venda. Assim, não há a divisão do dinheiro, como no primeiro caso, "entra tudo no bolo da casa" (B. C. D., apanhadora de mangaba, 45 anos). No entanto, antes da venda, seja ela realizada pelo homem ou pela mulher, o casal decide como será usado o dinheiro. Os casais que têm filhos, durante cada semana de venda, favorecem um ou dois filhos (compra de roupas, sapatos, material escolar etc.); assim, no final da safra da mangaba, todos os filhos terão sido beneficiados.
Além disso, em um dos casos desse arranjo, o homem estipula um valor para comprar cerveja ou cachaça, sem que isso provoque conflitos: “[...] eu mais que decido do que meu marido [como usar o dinheiro das vendas da mangaba], a gente gasta com a casa, mas a mulher tem mais coisa pra comprar que o homem, às vezes ele pega um dinheiro pra tomar cerveja" (B. C. D., apanhadora de mangaba, 45 anos).

Nas outras duas famílias que compõem o tipo 2, embora o homem não use o dinheiro para comprar bebida, a mulher tem menor poder de decisão sobre seu uso. As mulheres, neste caso, só vão às feiras da sede do município, e com menor frequência que os maridos. Essas são as famílias compostas pelo casal com filhos na primeira infância e adolescentes. Uma das mulheres desse grupo declarou como entende o trabalho de extrativismo da mangaba: "Mangaba é devagar, o preço é baixo, muito trabalho pra pouco dinheiro, dá mais trabalho a mangaba que o açaí e o bacuri. [...] Vou comprar milho do tio Tomé com o dinheiro da mangaba" (I. L. M., apanhadora de mangaba, 29 anos).

Em nossa opinião, essa é uma das mulheres que não tem autonomia em seu trabalho. Foi observado que nem mesmo a relação que ela tem com o trabalho é satisfatória, diferente de outras apanhadoras de mangaba, que apreciam o trabalho e acham que a safra da mangaba é o período do ano em que mais têm acesso a recursos financeiro próprios.

Apesar da insatisfação declarada, ela, assim como as outras mulheres, utiliza o dinheiro para comprar alimento para a criação de galinhas caipiras, atividade sob a sua responsabilidade.

Ainda em duas famílias do tipo 2, foi que constatado que o ciclo de reprodução familiar influencia significativamente na maior ou menor autonomia da mulher. As mulheres com filhos pequenos permanecem mais tempo em casa, vão às feiras com menor frequência e, embora no discurso o dinheiro da venda da mangaba seja usado de acordo com a decisão do casal, é o homem que tem maior poder de geri-lo, no caso de duas famílias do tipo 2. 
O que se pode concluir é que essas mulheres cedem o maior poder ao homem, não para atender aos seus desejos pessoais, mas porque acreditam que ele decide em conformidade com o que é "melhor" para a família.

Ainda em uma família do tipo 2, com filhos adultos, a mulher exerce maior autonomia, gerenciando sua força de trabalho, compartilhando com o marido todas as atividades, do extrativismo à comercialização, e exercendo poder na tomada de decisão quanto ao uso da renda gerada.

O tipo 3 é composto por duas apanhadoras de mangaba que desenvolvem todas as atividades sem o envolvimento dos maridos. Esse grupo é representado por duas mulheres. Os grupos domésticos nesse caso são compostos pelos pais com filhos tanto na idade adulta, quanto jovens e crianças. As mulheres assumem todo o processo extrativista (mangaba e guarumã), a fabricação dos paneirinhos e também a comercialização, que nesse caso é realizada apenas na feira da sede do município.

No primeiro caso, no grupo doméstico em que a mulher tem filhos adultos, ela opta por usar o seu dinheiro para garantir a alimentação de todos. Além disso, compra roupas e sapatos para ela.

No segundo caso, a mulher que tem filhos na primeira infância realiza o seu trabalho de coleta apenas nas manhãs, como já descrito anteriormente. O homem é o provedor, é ele quem compra produtos alimentícios; a mulher, por sua vez, usa o dinheiro da venda das mangabas com compras que beneficiam os filhos e ela mesma. Algumas vezes, ela compra bens duráveis, como ferramentas para o trabalho ou eletrodomésticos para a casa, com os recursos ganhos, ou a crédito nas lojas.

Essa apanhadora de mangaba explica como ela costuma usar o dinheiro obtido com a venda da fruta:

O dinheiro é meu, às vez compro alguma coisa, ajudo alguma coisa em casa, [...] e pros pequeno também, roupinha pra eles, sandália, o leitinho deles, e pra mim compro sandália, uma roupinha. É sempre bom ter o nosso dinheirinho né? Deus o livre, independente de marido (R. M., apanhadora de mangaba, 23 anos).

No depoimento, a mulher declara que o dinheiro obtido com a venda da mangaba proporciona maior independência.

No tipo 4, estão três grupos domésticos em que os homens praticam a atividade do extrativismo sem as esposas. São grupos compostos por pais e filhos tanto na primeira infância quanto jovens e adultos.

Nos dois grupos com filhos na primeira infância, a mãe assume o trabalho doméstico, além da criação de animais de pequeno e médio porte. $\mathrm{O}$ pai assume as atividades da roça, do extrativismo vegetal e animal. De acordo com uma das mulheres, o trabalho no extrativismo é muito fatigante, por isso, ela prefere criar porco e galinha. Nesse caso, a mulher, mesmo não trabalhando no extrativismo, negocia o uso do recurso obtido pelo marido, tendo um poder significativo sobre o usufruto da renda.

O outro caso desse arranjo é um casal com filhos adultos. A mulher era poupada do trabalho produtivo e também doméstico por estar recuperando-se de uma cirurgia, mas, mesmo antes da cirurgia, ela não praticava o extrativismo. Nesse caso, o homem, além do trabalho produtivo, também realizava o trabalho doméstico.

Do exame dos quatro tipos de grupos, conclui-se que o extrativismo da mangaba representa uma renda extra, usada na compra de produtos de primeira necessidade e também na compra de eletrodomésticos, roupas, calçados e material escolar. Além disso, parte é guardada para despesas futuras.

Como constatado, a safra da mangaba é o único período do ano em que as mulheres conseguem reservar uma pequena poupança, que é usada regradamente no decorrer do ano, por pelo menos oito meses depois da safra, quer seja com produtos para uso pessoal e dos filhos, quer seja na compra de milho e farelo para alimentar a criação de animais de pequeno e médio porte, atividades geridas pela mulher. 
Nesse sentido, o extrativismo da mangaba, que é uma atividade sazonal, entra no calendário produtivo também alimentando uma atividade que é contínua, colaborando com o desenvolvimento do trabalho economicamente produtivo gerenciado pela mulher não apenas durante a safra, mas também no correr do ano, ao subsidiar a criação dos animais, o que contribui positivamente para a maior autonomia da mulher, já que ela tem a possibilidade de gerenciar seu trabalho, gerando renda com sua mão de obra e usufruindo diretamente desta renda.

A autonomia naquele contexto está também associada ao arranjo e ao ciclo de reprodução do grupo familiar em que a mulher está inserida. A mulher com filhos na primeira infância, em todos os casos analisados, tem maior demanda de tempo para o trabalho doméstico e o cuidado com os filhos, mas esse não é um fator decisivo para a autodeterminação da mulher no trabalho economicamente produtivo.

A mulher do tipo 1, com filhos adolescentes e jovens, mesmo não indo às feiras vender a mangaba, tem maior autonomia em relação à gestão de seu trabalho e ao usufruto da renda do que as duas mulheres do tipo 2, com filhos crianças e adolescentes. Ainda, uma outra mulher classificada no tipo 2, que admite que o marido usa uma pequena porcentagem da renda para comprar bebidas alcoólicas, não tem sua força de trabalho subordinada ao marido, pois ela gerencia o trabalho e tem poder sobre o uso da renda.

As mulheres do tipo 3 são autônomas no que concerne à gestão de sua força de trabalho e também ao usufruto da renda gerada. Apesar disso, metade da amostra é composta por casais com filhos pequenos, e a outra metade é composta por mães sem marido e com filhos adultos, o que comprova que, ainda que o ciclo de reprodução familiar influencie, não é determinante da maior ou menor autonomia da mulher.

No tipo 4, no primeiro grupo doméstico, a mulher, mesmo com maiores dificuldades no trabalho de coleta da fruta, porque o trabalho doméstico exige mais, se comparada à outra, consegue gerir o seu trabalho no campo, vender a fruta e usar o dinheiro com autonomia.
De acordo com esse quadro, constata-se que as decisões sobre o uso do dinheiro estão relacionadas ao ciclo de reprodução, balizado pela demanda de cuidado com os filhos. Na maioria dos casos, a mulher tem autonomia em relação à sua força de trabalho e à decisão quanto ao uso dos recursos gerados, afastando-se, assim, do perfil traçado pela literatura, que aponta a subordinação da força de trabalho da mulher ao homem na agricultura familiar.

\section{Conclusões}

O objetivo deste artigo foi analisar o trabalho da mulher no extrativismo da mangaba, sob o foco da autonomia, para organizar e desenvolver o trabalho produtivo, definindo seus propósitos e agindo em consequência deles, assim como a capacidade de gerar renda e de decidir a forma como ela será utilizada. Para isso, foi realizado um estudo de caso com mulheres que se autodenominam apanhadoras de mangaba na localidade de Espírito Santo, Campo da Mangaba, município de Maracanã, estado do Pará. No estudo, verificou-se a valorização da mangaba nos mercados e o reconhecimento da importância das mulheres no extrativismo, quer pela sua maior visibilidade no espaço público, quer pelos recursos que aportam para o aumento da renda familiar (MOTA, SCHMITZ e FREITAS, 2007; SANTOS, 2007).

Analisando os ciclos de reprodução, os arranjos para a organização do trabalho postos em prática e o uso da renda gerada por todos os grupos domésticos residentes na localidade, conclui-se que o principal fator que contribui para a maior ou menor autonomia da mulher é a autodeterminação que é construída a partir das experiências individuais de cada uma. Além disso, há grupos domésticos nos quais as mulheres conseguem estabelecer pactos conjugais com o companheiro e com os filhos. Já em outros, as mulheres encontram resistência ou mesmo não se veem como capazes de construir novas posições na família e na sociedade, sendo o ciclo de reprodução 
relevante, mas não determinante para maior ou menor autonomia da mulher.

Conclui-se também que o trabalho da mulher no extrativismo da mangaba faz parte de um elenco de atividades que se inter-relacionam e se alimentam reciprocamente. Entretanto, é a renda advinda dessa atividade que concede maior poder de compra, além de possibilitar guardar dinheiro para eventualidades e para subsidiar outras atividades, como a criação de pequenos animais. Portanto, a renda obtida com a venda dos frutos da mangaba oferece suporte financeiro à mulher e à família no correr do ano, mesmo nos períodos fora da safra. Além disso, estimula uma atividade contínua, a criação de pequenos e médios animais, que também é desenvolvida pela mulher, o que contribui positivamente para a sua maior autonomia.

Conclui-se que, em seis dos nove casos analisados, o trabalho da mulher no extrativismo é feito com autonomia, tanto a coleta e o beneficiamento, quanto a comercialização e o uso da renda. Em três, no entanto, as mulheres não têm autonomia em seu trabalho. A autonomia assume forma diferente, dependendo do ciclo de reprodução do grupo doméstico, dos pactos familiares e, principalmente, da autodeterminação de cada mulher.

As mulheres atuam de acordo com o contexto local e com a posição específica que ocupam na família, na localidade ou nas relações mais amplas. Nesse sentido, entende-se que a comparação feita entre os dados deste trabalho quanto sobre o trabalho da mulher no extrativismo da mangaba e a bibliografia que trata o trabalho da mulher no espaço rural e principalmente na agricultura, mostra que, na primeira atividade, a mulher tem maior possibilidade de autonomia. Este pode ser um campo de análise interessante a ser mais profundamente estudado.

Como conclusão geral, este artigo concorda com Paulilo (2004) e Melo (2003): é necessário o acesso a um recurso financeiro para que a mulher possa ter maior autonomia. Essa condição é necessária, mas não suficiente, porque não se pode esquecer o papel central da autodetermina- ção, que é condicionada por predisposições culturais e traços individuais.

De acordo com Scherer-Warren (1989), as formas de analisar os movimentos de mudança no papel das mulheres na sociedade e no trabalho são variadas. Podem considerar um projeto de transformação global da sociedade a partir de sujeitos históricos definidos ou pequenas transformações que vão ocorrendo no cotidiano. É essa última concepção que mais se aproxima do perfil das mulheres analisadas neste estudo: elas não participam de organizações sociais políticas em busca de autonomia, mas, no cotidiano do trabalho e da vida, agem nesse sentido.

O trabalho concorda, então, com Perrot (1996), para quem as representações do poder das mulheres persistem como um imenso tema de investigação histórica e antropológica.

\section{Referências bibliográficas}

ALMEIDA, A. W. B. de e PEREIRA, D. D. de B. As populações remanescentes de quilombos: direitos do passado ou garantia para o futuro? In: RIOS, A. V.; COSTA, F. D. de C. (Org.). As minorias e o Direito. Seminário Internacional. Brasília, DF: Conselho de Justiça Federal: Centro de Estudos Jurídicos, 2003. p. 243-266.

BRUMER, A. Gênero e agricultura: a situação da mulher na agricultura no Rio Grande do Sul. Revistas Estudos Feministas, Florianópolis, v. 12, n. 1, p. 205-227, jan./abr. 2004.

CORDEIRO, R. de L. M. Empoderamento e mudança das relações de gênero: as lutas das trabalhadoras rurais no Sertão Central de Pernambuco. In: SCOTT, P. e CORDEIRO, R. de L. M. (Org.). Agriculturas familiares e gênero: práticas, movimentos e políticas públicas. Recife: UFPE, 2006. p. 147-171.

D'INCAO, M. Â. e COTTA JÚNIOR, H. Transformação e permanência no espaço feminino na agricultura familiar. In: D'INCAO, M. Â., ÁLVARES, M. L. M. e SANTOS, E. F. dos (Org.). Mulher e modernidade na Amazônia. Belém: GEPEM: CFCH: UFPA, 2001. p. $429-465$.

ESTERCI, N. Populações tradicionais. In: INSTITUTO SOCIOAMBIENTAL. Almanaque Brasil Socioambiental. São Paulo, 2005. p. 223-225. 
FARIA, N. Economia feminista e agenda de luta das mulheres no meio rural. In: DI SABATO, A., MELO, I. P., LOMBARD, M. R., FARIA, N. e BRITO, A. (Org.). Estatísticas rurais e a economia feminista: um olhar sobre o trabalho das mulheres. Brasília: MDA, 2009.

FERNANDES, T. Entre campo e casa: a autonomia da mulher e o extrativismo da Mangaba. 2011. 138 f. Dissertação (Mestrado em Agriculturas Familiares e Desenvolvimento Sustentável) - Centro Agropecuário, Núcleo de Estudos Integrados sobre Agricultura Familiar, Empresa Brasileira de Pesquisa Agropecuária-Amazônia Oriental, Universidade Federal do Pará, Belém, 2011.

FIGUEIREDO, L. D. Empates nos babaçuais: do espaço doméstico ao espaço público - lutas de quebradeiras de coco babaçu no Maranhão. 2005. 190 f. Dissertação (Mestrado em Agriculturas Familiares e Desenvolvimento Sustentável) - Centro Agropecuário, Núcleo de Estudos Integrados sobre Agricultura Familiar, Empresa Brasileira de Pesquisa AgropecuáriaAmazônia Oriental, Universidade Federal do Pará, Belém, 2005.

MELO, L. A. de. Relações de gênero na agricultura familiar: o caso do PRONAF em Afogados da Ingazeira-PE. Recife: UFPE, 2003.

MOTA, D. M. da, SCHMITZ, H. e FREITAS, M. N. Pesquisa e agricultura familiar: contribuição para o debate. In: ENCONTRO DA REDE DE ESTUDOS RURAIS, 2., 2007, Rio de Janeiro. Anais... Rio de Janeiro: CPDA: UFRRJ, 2007. p. 1-9.

MOTA, D. M. da e SCHMITZ, H.; SILVA JÚNIOR, J. F. da. O extrativismo em tempos de globalização no Nordeste brasileiro. In: CONGRESSO BRASILEIRO DE SOCIOLOGIA, 13., 2007, Recife. Anais..., Recife: SBS, 2007. 1CD-ROM.

MOTA, D. M. da, SCHMITZ, H., SILVA JÚNIOR, J. F. da e RODRIGUES, R. F. de A. Extrativismo da mangaba: isso é trabalho de mulher? In: SEMINÁRIO INTERNACIONAL - AMAZÔNIA E FRONTEIRAS DO CONHECIMENTO, 2008, Belém. Anais... Belém, Núcleo de Altos Estudos Amazônicos, 2008a. 1CD-ROM.

MOTA, D. M. da, SILVA JÚNIOR, J. F. da, SCHMITZ, H. e RODRIGUES, R. F. de A. (Ed.). A mangabeira, as catadoras, o extrativismo. Belém: Embrapa Amazônia Oriental, Embrapa Tabuleiros Costeiros, 2010.

MOTA, D. M. da, SILVA JÚNIOR, J. F. da, SCHMITZ, H. e BRITO, J. V. dos S. As senhoras da mangaba. In: MOTA, D. M. da, SILVA JÚNIOR, J. F. da, SCHMITZ, H. e RODRIGUES, R. F. de A. (Ed.). A mangabeira, as catadoras, o extrativismo. Belém: Embrapa, 2011a. p. 105-137.
MOTA, D. M. da, SCHMITZ, H., SILVA JÚNIOR, J. F. da e BRITO, J. V. dos S. Trabalho familiar e sociabilidade no extrativismo da mangaba. In: MOTA, D. M. da, SILVA JÚNIOR, J. F. da, SCHMITZ, H. e RODRIGUES, R. F. de A. (Ed.). A mangabeira, as catadoras, o extrativismo. Belém: Embrapa, 2011b. p. 141-167.

MOTTA-MAUÉS, M. A. "Trabalhadeiras" e "camarados": relações de gênero, simbolismo e ritualização numa localidade amazônica. Belém: Centro de Filosofia e Ciências Humanas da UFPA, 1993.

MURPHY, Y. e MURPHY, R. F. Women of the Forest. New York: Columbia University Press, 1974.

OLIVEIRA, M. C. S., PEREIRA, N. G. e PAES, J. V. S. Parecer técnico: visita efetuada a área denominada Campo da Mangaba. Belém: Secretaria de Estado e Meio Ambiente, 2007.

OSSAMI DE MOURA, M. C. O meio ambiente e a espiritualidade entre os povos indígenas no Brasil. Revista de Divulgação Científica do IGPA, Goiânia, v. 4, p. 7-20, 2001.

PAULILO, M. Trabalho familiar: uma categoria esquecida de análise. Revista Estudos Feministas, Florianópolis, v. 12, n. 1, p. 1-18, 2004.

PEREIRA, E. O. Extrativismo da mangaba (Hancornia speciosa Gomes) no Povoado Alagamar, Pirambu - SE, 2008, 102 f. Dissertação (Mestrado em Agroecossistemas) - Programa de Pós-Graduação e Pesquisa em Agroecossistemas, Núcleo de Pós-Graduação em Estudos e Recursos Naturais, Universidade Federal de Sergipe. São Cristóvão, 2008.

PERROT, M. A juventude operária: da oficina a fábrica. In: LEVI, G. e SCHMITT, J-C. (Org.). História dos jovens 2: a época contemporânea. São Paulo: Companhia das Letras, 1996. cap. 4.

RAFFLES, H. In Amazonia: a natural history. [S.1.]: Princeton University Press, 1999.

SABOURIN, E. Práticas de reciprocidade e economia de dádiva em comunidades rurais do Nordeste brasileiro. Revista Raízes, Campina Grande, v. 18, n. 20, p. 41-49, nov. 2001.

SANTOS, J. V. dos. O papel das mulheres na conservação das áreas de remanescentes de mangabeiras (Hancornia speciosa Gomes) em Sergipe. 2007. 103 f. Dissertação (Mestrado em Agroecossistemas) - Programa de PósGraduação e Pesquisa em Agroecossistemas, Núcleo de Pós-Graduação em Estudos e Recursos Naturais, Universidade Federal de Sergipe. São Cristovão, 2007. 
SCHERER-WARREN, I. Cidadania sem fronteiras: ações coletivas na era da globalização. São Paulo: Hucitec, 1989.

SCHMITZ, H., MOTA, D. M. da, SILVA JÚNIOR, J. F. da. Mangabeiras cercadas e soltas: formas de acesso, coleta e gestão das plantas. In: MOTA, D. M. da, SILVA JÚNIOR, J. F. da, SCHMITZ, H. e RODRIGUES, R. F. de A. (Ed.). A mangabeira, as catadoras, o extrativismo. Belém: Embrapa, 2011. p. 171-202.

SILVA, C. e PORTELLA, A. P. Divisão sexual do trabalho em áreas rurais no Nordeste brasileiro. In: SCOTT, R. P. e CORDEIRO, R. de L. M. (Org.). Agriculturas familiares e gênero: práticas, movimentos e políticas públicas. Recife: UFPE, 2006. p. 127-144.

SILVA JÚNIOR, J. F. da, MOTA, D. M. da e SCHMITZ, H. No rastro da mangabeira. In: MOTA, D. M. da, SILVA JÚNIOR, J. F. da, SCHMITZ, H. e RODRIGUES, R. F. de A. (Ed.). A mangabeira, as catadoras, o extrativismo. Belém: Embrapa, 2011. p. 45-76.
SIMMEL, G. Sociabilidade: um exemplo de sociologia pura ou formal. In: MORAES FILHO, E. de (Org.). Simmel. São Paulo: Ática, 1983 (Coleção Os Grandes Cientistas Sociais).

SIMONIAN, L. T. L. Mulheres seringueiras na Amazônia brasileira: uma vida de trabalho silenciado. In: ÁLVARES, M. L. M. e D'INCAO, M. Â. (Org.). A mulher existe? Uma contribuição ao estudo da mulher e gênero na Amazônia. Belém: MPEG, 1995. p. 97-115.

SIMONIAN, L. T. L. Mulheres, cultura e mudança nos castanhais do Sul do Amapá. In: SIMONIAN, L. T. L. Mulheres da floresta Amazônica: entre o trabalho e a cultura. Belém: UFPA: NAEA, 2001. p. 107-148.

WOORTMANN, K. e WOORTMANN, E. F. Monoparentalidade e chefia feminina: conceitos, contextos e circunstâncias. 2004. 99 p. Disponível em: <http://www.abep.nepo.unicamp.br/XIIIencontro/ woortmann.pdf > . Acesso em: 18 abr. 2012. 